\title{
MORPHOMETRIC DISCRIMINANT ANALYSIS OF THREE SPECIES of Petasiger Dietz, 1909 (Digenea: Echinostomatidae)
}

\author{
KOSTADINOVA A.*, GIBSON D.I.** \& GUBÁNYI A.***
}

\section{Summary :}

The morphology of three Palaearctic species of the genus Petasiger Dietz, 1909, parasitizing grebes and exhibiting a significant degree of overlap, was studied. Ninety-three specimens belonging to $P$. grandivesicularis, $P$. neocomense and $P$. pungens were compared using univariate and multivariate statistical analyses of 17 metrical characters. A stepwise discriminant analysis run in three variants and based on seven variables (body length, body width, oral sucker diameter, pharynx diameter, ventral sucker diameter, posterior testis diameter and oesophagus lengthl yielded a $100 \%$ accurate classification. The first canonical discriminant function separated specimens belonging to

$P$. grandivesicularis and $P$. pungens, and the second function effectively differentiated the $P$. neocomense sample. Two variables (pharynx diameter and oesophagus length) were strongly correlated with the canonical functions and, when used alone, discriminated the three Petasiger spp. A simple key based on two variables used in the discriminant analyses and a table of the qualitative and quantitative characters used for the identification of the three species are presented

KEY WORDS : Digenea, Echinostomatidae, Petasiger, Petasige grandivesicularis, Petasiger neocomense, Petasiger pungens, morphology, variability, multivariate analysis.

\section{INTRODUCTION}

S ince the erection of the genus Petasiger by Dietz (1909) for a new species, P. exaeretus Dietz, 1909, from cormorants, 13 species of Petasiger have been described from grebes (Aves: Podicipedidae). Of these, six species $[P$. pungens (Linstow, 1894), P. megacanthum (Kotlan, 1922), P. neocomense Fuhrmann, 1927, P. lobatus Yamaguti, 1933, P. grandivesicularis Ishii, 1935, and P. brevicauda (Ishii,

\footnotetext{
* Department of Biodiversity, Central Laboratory of General Ecology, Bulgarian Academy of Sciences, 2 Gagarin Street, 1113 Sofia, Bulgaria.

** Department of Zoology, The Natural History Museum, London SW7 5BD, UK.

*** Zoological Department, Hungarian Natural History Museum, Baross u. 13, H-1088 Budapest, Hungary.

Correspondence: Aneta Kostadinova.

Fax : (3592) 705498

E-mail : akk@bgcict.acad.bg.
}

Résumé : ANALYSE MORPHOMÉtRIQUE DISCRIMINANTE DE TROIS ESPÈCES de Petasiger Dietz, 1909 (Digenea : Echinostomatidae)

La morphométrie de trois espèces voisines paléarctiques du genre Petasiger Dietz, 1909 parasitant les grèbes est étudiée. Quatrevingt treize spécimens adultes de P. grandivesicularis, $P$. neocomense et $P$. pungens ont été comparés à l'aide d'analyses unifactorielles et multifactorielles de 17 paramètres morphométriques. L'analyse discriminante, exécutée en trois variantes et basée sur sept variables /longueur et largeur du corps, diamètres de la ventouse orale, du pharynx, de la ventouse ventrale et du testicule postérieur, et longueur de l'œsophagel, a permis une identification $100 \%$ exacte. La première fonction canonique discriminante a différencié les spécimens de $P$. grandivesicularis et $P$. pungens tandis que la deuxième fonction différencie le groupe $P$. neocomense des deux autres. Deux variables (diamètre du pharynx et longueur de l'œsophage) présentent une grande corrélation avec les fonctions canoniques et à elles seules permettent d'identifier les trois espèces de Petasiger. Une clé construite à partir de ces deux variables identifées par l'analyse discriminante ainsi qu'un tableau décrivant les caractères qualitatits et quantitatifs utilisés pour l'identification des trois espèces sont proposés.

MOTS CLÉS : Digenea, Echinostomatidae, Petasiger, Petasiger grandivesicularis Petasiger neocomense, Petasiger pungens, morphologie, variabilité, analyse multifactorielle.

1935)] were recorded within the Palaearctic, six species ( $P$. nitidus Linton, 1928, P. novemdecim Lutz, 1928, P. chandleri Abdel-Malek, 1952, P. floridus Premvati, 1968, P. pseudoneocomense Bravo-Hollis, 1969 , and $P$. caribbensis Nassi, 1980) were described from the New World and one ( $P$. australis Johnston and Angel, 1941) occurs in Australia.

Although the generic status of these species has been questioned (see Prudhoe, 1945; Odening, 1962), they all appear to constitute a natural group of grebe-specific parasites, all possessing 19 collar spines. However, the members of this flock of closely related species exhibit a significant degree of overlap in the morphometric characters, which, added to the lack of reliable qualitative differential features, has lead in many cases to taxonomic uncertainties (see Prudhoe, 1945; Skrjabin \& Bashkirova, 1956; Odening, 1962; Nasir et al., 1972; Kostadinova \& Gibson, in press). As no study of the intraspecific variability of adult morphology of the 19 collar-spined Petasiger species complex has been undertaken, a detailed analysis of 
metrical features of the three most common Palaearctic species, $P$. grandivesicularis, $P$. neocomense and $P$. pungens, is presented here. In addition, since only sample ranges for measurements have previously been presented for all documented records of Petasiger spp., an attempt will be made to test statistically differences in the metrical features of the three species using newly-collected materials in order to elucidate those which are the most discriminating.

\section{MATERIALS AND METHODS}

\section{PARASITE MATERIALS}

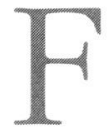

our sets of adult worms were examined: one set from Japan and three sets from Bulgaria. The latter included 21 specimens of $P$. grandivesicularis and 20 specimens of $P$. pungens from the small intestine of Tachybaptus ruficollis, and 24 specimens of $P$. neocomense from the small intestine of Podiceps cristatus. Birds were collected on the Bulgarian Black Sea coast (Lake Durankulak). The Japanese set included 28 voucher specimens of $P$. grandivesicularis from the small intestine of T. ruficollis japonicus from Lake Ogura, Japan, originally described by Yamaguti (1939).

All of the Bulgarian material was collected live, killed and fixed in hot water, preserved in $70 \%$ alcohol, stained with iron-acetocarmine, which also acts as a fixative (Georgiev et al., 1986), and mounted in Canada balsam (AK collection Nos 10121, 14626, 10065, 11156). The Japanese specimens deposited in the Meguro Parasitological Museum (No. 22609, SY7001) have been fixed in acetic sublimate under a cover glass, stained with Heidenhain's hematoxylin and mounted in balsam. Measurements are given in micrometres.

The morphology of our material agreed with the original descriptions and also corresponded well with the subsequent redescriptions of the three species under study (Prudhoe, 1945; Macko, 1959; Odening, 1962, 1965; Borgarenko, 1984; Chen et al., 1985).

\section{STATISTICAL ANALYSES}

The following metrical features (variables) were subjected to analyses (see Fig. 1 and Table I) :

1. Body length (BL); 2. Maximum body width (BW); 3. Head collar width $(\mathrm{CW})$; 4. Angle spines length (ASL) ; 5. Dorsal spines length (DSL); 6. Oral sucker diameter (DOS); 7. Prepharynx length (PL); 8. Pharynx diameter (DPH); 9. Oesophagus length (OL); 10. Cirrus-sac length (CSL); 11. Maximum cirrus-sac width (CSW); 12. Ventral sucker diameter (DVS); 13. Anterior testis diameter (DAT); 14. Posterior testis diameter (DPT); 15. Ovary diameter (DOV); 16. Egg length (EL); 17. Egg width (EW).

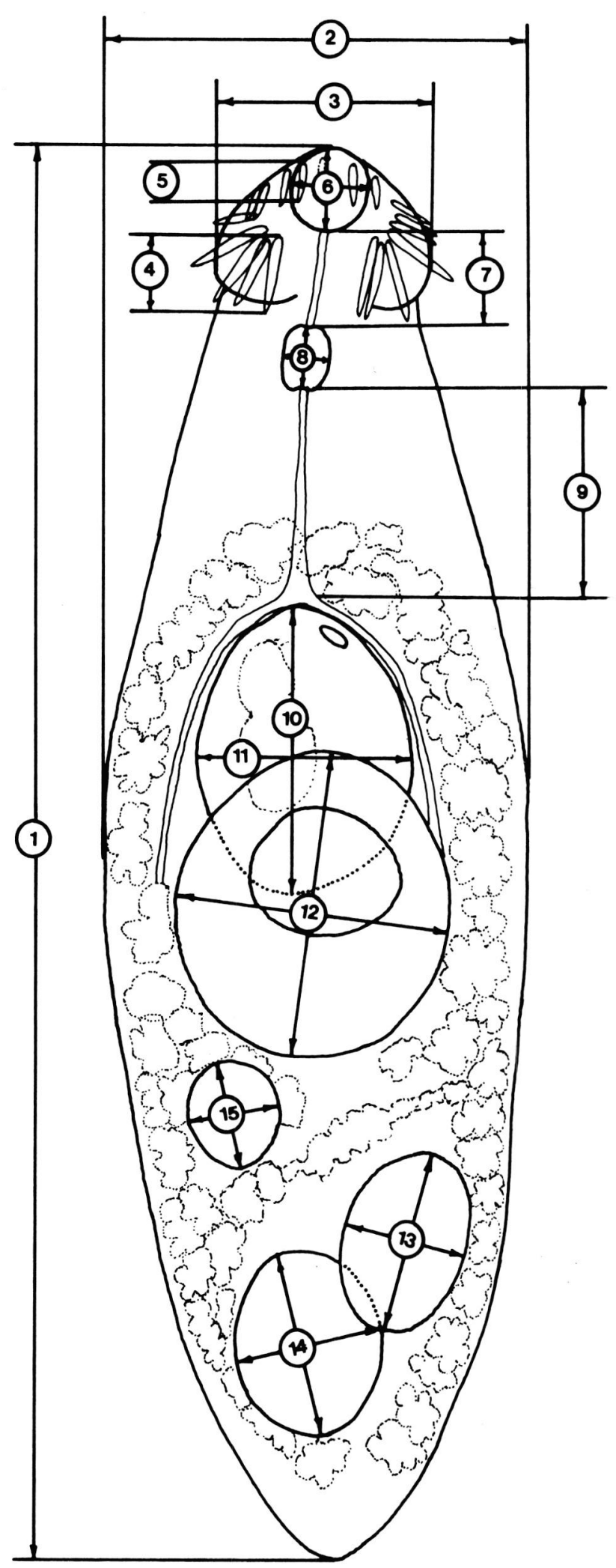

Fig. 1 - Schematic illustration of Petasiger grandivesicularis, showing the metrical features used as variables in the analyses. 


\begin{tabular}{|c|c|c|c|c|c|c|c|c|c|}
\hline \multirow{2}{*}{$\begin{array}{c}\text { Species } \\
\text { No. Variable }\end{array}$} & \multicolumn{3}{|c|}{ P. grandivesicularis } & \multicolumn{3}{|c|}{ P. neocomense } & \multicolumn{3}{|c|}{ P. pungens } \\
\hline & $n$ & Mean & Lo-Up CLs & $n$ & Mean & Lo-Up CLs & $n$ & Mean & Lo-Up CL \\
\hline 1. $\mathrm{BL}$ & 49 & 1,005 & $973-1,040$ & 24 & 1,349 & $1,277-1,425$ & 20 & 1,528 & $1,426-1,637$ \\
\hline 2. BW & 48 & 320 & $304-337$ & 23 & 395 & $367-426$ & 20 & 478 & $457-500$ \\
\hline 3. CW & 46 & 155 & $149-162$ & 22 & 216 & $199-235$ & 17 & 207 & $198-217$ \\
\hline 4. ASL & 199 & 69 & $67-70$ & 46 & 85 & 83-88 & 18 & 78 & $73-84$ \\
\hline 5. DSL & 83 & 40 & $39-41$ & 47 & 66 & $63-69$ & 12 & 49 & $45-53$ \\
\hline 6. DOS & 49 & 60 & $58-62$ & 24 & 82 & $78-87$ & 20 & 101 & $98-104$ \\
\hline 7. PL & 47 & 53 & $49-57$ & 23 & 54 & $46-64$ & 15 & 45 & $32-64$ \\
\hline 8. DPH & 48 & 45 & 44-46 & 24 & 63 & $60-65$ & 19 & 81 & $78-84$ \\
\hline 9. OL & 45 & 130 & $124-138$ & 24 & 275 & $250-303$ & 16 & 138 & $117-163$ \\
\hline 10. CSL & 32 & 157 & $145-170$ & 20 & 192 & $178-207$ & 5 & 186 & $177-196$ \\
\hline 11. CSW & 37 & 142 & $126-161$ & 21 & 105 & 95-116 & 3 & 130 & $117-143$ \\
\hline 12. DVS & 49 & 216 & $207-226$ & 24 & 270 & $252-290$ & 20 & 256 & $247-264$ \\
\hline 13. DAT & 34 & 136 & $129-142$ & 24 & 149 & $138-160$ & 18 & 189 & $179-201$ \\
\hline 14. DPT & 46 & 128 & $122-135$ & 24 & 140 & $130-150$ & 20 & 197 & $182-214$ \\
\hline 15. DOV & 19 & 75 & $67-85$ & 17 & 67 & $59-74$ & 16 & 78 & $72-85$ \\
\hline 16. EL & 28 & 78 & $76-81$ & 25 & 71 & $68-74$ & 19 & 83 & $80-87$ \\
\hline 17. EW & 28 & 49 & $47-52$ & 25 & 43 & $41-45$ & 19 & 46 & $43-49$ \\
\hline
\end{tabular}

Table I. - Means and their confidence intervals (Lo-Up $95 \%$ confidence limits) for variables under comparison.

Approximate diameters (for Nos 6, 8, 12, 13, 14 and 15) were calculated as: (length + width)/2. Prior to analysis the data were log-transformed $\left(\log _{10}\right)$. Firstly, the descriptive univariate statistics [mean values, standard deviations and $95 \%$ confidence limits (CLs)] for all of the variables were calculated for every species. Then one-way analyses of variance (ANOVA) were carried out to test the equality of the species means for each variable (Sokal \& Rohlf, 1981).

A set of variables selected at the second step was submitted to discriminant analysis using the species as a grouping variable. The forward stepwise variable selection procedure was applied using the minimization of Wilks' lambda as a selection criterion. Specimens with a missing value for most of the variables were not included in the canonical analysis: these were two specimens from the Bulgarian set and four specimens from the Japanese set of P. grandivesicularis; four P. pungens; and one $P$. neocomense. Since cases with missing information for any of the predictor variables were excluded from the analyses, some variables showing high numbers of missing values were eliminated in order to increase the sample size. As a result, seven variables (BL, BW, DOS, DPH, DVS, DPT and OL) and 82 specimens were used.

Since $i$ ) the measurements of the Japanese set of P. grandivesicularis (described by Yamaguti, 1939) varied outside the limits given by Ishii (1935) and ii) the univariate statistical tests revealed significant differences between the two samples of this species (Bulgarian and Japanese) in 13 of the 17 metrical features $(\mathrm{P}<0.05$; data not shown), the analysis was run in three variants. Canonical variates from distance mea- surements for each species were computed using: i) data from the pooled $P$. grandivesicularis set [82 cases (43 P. grandivesicularis, 23 P. neocomense and $16 P$.pungens)]; $i$ ) data from the Japanese subset of specimens of $P$. grandivesicularis $[63$ cases (24 P. grandivesicularis, 23 P. neocomense and 16 $P$. pungens)]; iii) data from the Bulgarian subset of specimens of $P$. grandivesicularis $[58$ cases (19 P. grandivesicularis, 23 P. neocomense and 16 P. pungens)]. After the variables considered to be the most discriminating had been chosen, a simple classification key was prepared. The threshold values used in the key were calculated as described by Di Deco et al. (1994). All statistical analyses were performed using SPSS/PC+ (Norusis, 1990) at the Hungarian Natural History Museum.

\section{RESULTS}

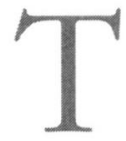

he means of the metrical features of $P$. grandivesicularis (the two sets pooled), $P$. neocomense and $P$. pungens and their confidence intervals are given in Table I. In order to estimate which of the 17 metrical features might be useful for the identification of the three Petasiger species, their means and $95 \%$ confidence limits were examined for overlap between the three sets. Five variables (BL, BW, DSL, DOS and DPH) showed no overlap of any kind. Four other characters (CW, ASL, CSL and DVS), although having close mean values and overlapping confidence intervals for $P$. neocomense and $P$. pungens sets, separated the $P$. grandivesicularis set. 
Differences in measurements of the variables were tested statistically. The one-way analysis of variance revealed highly significant differences in the means of 15 of the 17 variables among the three species (Table II).

\begin{tabular}{lrccc}
\hline No. Variable & df & F & P & $\begin{array}{c}\text { Homogeneous } \\
\text { groups* }\end{array}$ \\
\hline 1. BL & 92 & 88.28 & $* * *$ & - \\
2. BW & 90 & 45.06 & ${ }^{* * *}$ & - \\
3. CW & 84 & 44.96 & $* * *$ & $(2+3)^{* *}$ \\
4. ASL & 262 & 65.62 & $* * *$ & - \\
5. DSL & 141 & 170.55 & ${ }^{* * *}$ & - \\
6. DOS & 92 & 194.39 & $* * *$ & - \\
7. PL & - & - & - & - \\
8. DPH & 90 & 359.72 & $* * *$ & - \\
9. OL & 84 & 109.91 & $* * *$ & $(1+3)$ \\
10. CSL & 56 & 7.56 & $* * *$ & $(2+3)+(3+1)$ \\
11. CSW & - & - & - & - \\
12. DVS & 92 & 22.01 & $* * *$ & $(2+3)$ \\
13. DAT & 75 & 28.25 & $* * *$ & $(2+1)$ \\
14. DPT & 89 & 42.18 & $* * *$ & $(2+1)$ \\
15. DOV & - & - & - & - \\
16. EL & 71 & 21.09 & $* * *$ & - \\
17. EW & 71 & 10.94 & $* * *$ & $(1+3)+(3+2)$ \\
\hline
\end{tabular}

* Groups in which the means are not significantly different from one another (Tukey test, rejection level 0.05).

** $1=P$. grandivesicularis set $; 2=P$. neocomense set $;=P$. pun gens set.

${ }_{* * *} \mathrm{P}<0.001 ;-\mathrm{P}>0.05$

Table II. - Significance of variation among the three species of Petasiger as shown by the ANOVA results.

In general, with the exception of the width of cirrussac and egg size, $P$. grandivesicularis exhibited the smallest dimensions of the metrical features compared. $P$. neocomense had the longest angle and dorsal spines, longest oesophagus and largest ventral sucker. The $P$. pungens set was characterized by the largest body, oral sucker, pharynx, testes and ovary. These results indicate that there are enough grounds for the three Petasiger species under study to be distinguished on the basis of the metrical variables discussed above. Consequently, the characters presented in Table III are proffered as being useful for the discrimination of the three commonest Palaearctic species of Petasiger. This also includes, in addition to the metric variables commented upon above, some qualitative features which were re-examined during the course of the study.

A stepwise discriminant analysis run to examine which variables best separate the three species sets revealed a combination of seven variables (BL, BW, DOS, DPH, DVS, DPT and OL) which yielded a $100 \%$ correct identification of the three taxa in all three variants (see Materials and Methods for details).
Both canonical discriminant functions (CDFs) had small values of Wilks' lambda (0.015 and 0.19; 0.009 and 0.199 ; and 0.007 and 0.146 for the three analyses, respectively) and were significant (Chi-squared approximation, $p<0.0001)$ in all three variants. The first function accounted for $74.5,77.9$ and $84.2 \%$ of the total between-species variability in the first, second and third variants, respectively, while the second accounted for the remaining 25.5, 15.8 and $22.1 \%$ of the variability, respectively. As illustrated in Fig. 2 A, the first CDF clearly separated specimens belonging to P. grandivesicularis and $P$. pungens, and the second CDF effectively differentiated the $P$. neocomense sample in all three variants.

Comparative data on the factor structure matrix (Table IV) showed that two variables (DPH and OL) were the most important features for discriminating the three Petasiger species along CDF1 and CDF2, respectively. These variables also exhibited the lowest correlation with the other predictor variables $(\mathrm{OL}$, range 0.20-0.47; DPH, range 0.28-0.47), and subsequent analysis showed that a combination of DPH and OL alone was sufficient to discriminate the three Petasiger species $(100 \%$ accurate classification; see also the ordination pattern in Fig. 2 B).

Finally, a simple classification key, in which the actual values for pharynx width were used rather than the calculated diameters, was constructed. The means and standard deviations of the oesophageal length (OL) for $P$. grandivesicularis and $P$. pungens (pooled) (135.9 \pm 30.9) were used to obtain the threshold value for the first step. Then the threshold value of the pharynx width (PHW) between $P$. pungens and $P$. grandivesicularis was calculated for the second step. These steps resulted in the following key:
(1) $\mathrm{OL}>185 \mu \mathrm{m}$
P. neocomense
$<185 \mu \mathrm{m}$
(2) PHW $>52 \mu \mathrm{m}$ P. pungens
$<52 \mu \mathrm{m}$ $P$. grandivesicularis

\section{DISCUSSION}

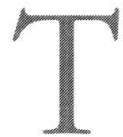

here has been considerable comment in the literature on the morphological criteria used for distinguishing the 19-collar spined forms of Petasiger at the specific level, as well as whether groupings at the subgeneric level exist (Bashkirova, 1941; Mendheim, 1943; Skrjabin \& Bashkirova, 1956; Yamaguti, 1958). Prudhoe (1945) re-described "Petasiger " pungens and " $P$." megacanthus, which he provisionally assigned to Petasiger and regarded $P$. neocomense and $P$. nitidus as synonyms of " $P$. " megacanthus. This author suggested that $P$. lobatus, $P$. grandivesicularis and $P$. australis bear a strong resemblance to " $P$. " pun- 


\begin{tabular}{|c|c|c|c|}
\hline Character & P. grandivesicularis & P. neocomense & P. pungens \\
\hline Body shape & $\begin{array}{l}\text { fusiform; widest } \\
\text { anterior to ventral } \\
\text { sucker }\end{array}$ & $\begin{array}{l}\text { fusiform; widest } \\
\text { at level of ventral } \\
\text { sucker }\end{array}$ & $\begin{array}{l}\text { elongate-oval; } \\
\text { widest posterior } \\
\text { to ventral sucker }\end{array}$ \\
\hline Cirrus & bulb-like & long, tubular & bulb-like \\
\hline Pars prostatica & well developed & not developed & intermediate \\
\hline Vitellarium & $\begin{array}{l}\text { large follicles forming } \\
\text { two fields fusing at } \\
\text { intestinal bifurcation } \\
\text { and posteriorly to ventral } \\
\text { sucker and testes }\end{array}$ & $\begin{array}{l}\text { small follicles in } \\
\text { two non-fusing } \\
\text { fields }\end{array}$ & $\begin{array}{l}\text { large follicles } \\
\text { in two fields } \\
\text { fusing posterior } \\
\text { to testes }\end{array}$ \\
\hline Testes & oblique & oblique & tandem, rarely oblique \\
\hline Body and organ size & smallest & intermediate & largest \\
\hline Collar spines & smallest & largest & intermediate \\
\hline Angle spines (CLs) & $67-70$ & $83-88$ & $73-84$ \\
\hline Dorsal spines (CLs) & $39-41$ & $63-69$ & $45-53$ \\
\hline Eggs & intermediate & smallest & largest \\
\hline Length (CLs) & $76-81$ & $68-74$ & $80-87$ \\
\hline Width (CLs) & $47-52$ & $41-45$ & $43-49$ \\
\hline \multicolumn{4}{|c|}{ Metrical features (in relation to body length): } \\
\hline Body width & intermediate & smallest & largest \\
\hline Collar width & intermediate & largest & smallest \\
\hline Prepharynx length & largest & intermediate & smallest \\
\hline Oesophagus length & intermediate & largest & smallest \\
\hline Ventral sucker diam. & intermediate & largest & smallest \\
\hline Posterior testis diam. & smallest & intermediate & largest \\
\hline
\end{tabular}

Table III. - Characters useful for distinguishing the three Palaearctic species of Petasiger.

gens. Nasir et al. (1972) went further, placing in synonymy with $P$. pungens the following: $P$. australis, $P$. chandleri, $P$. brevicauda, $P$. floridus, $P$. grandivesicularis, P. lobatus, P. longicirratus Ku, 1938, "P. parvispinosus " [sic] and P. spasskyi Oschmarin, 1974. Assuming that both metrical and qualitative features previously used to separate the adult parasites are subject to intraspecific variation, these authors suggested retaining the above species as conspecific unless lifehistory studies were able to furnish evidence to the contrary.

Obviously, further work is needed on both the life-history and adult morphology of Petasiger spp. Nevertheless, at the present time, adult morphology is all we have in most cases to provide criteria for erecting new species within the genus Petasiger, for the identification of Palaearctic material and for solving taxonomic problems, since life-history data for the Palaearctic species are almost non-existent (Karmanova, 1971; Kostadinova \& Chipev, 1992). Unfortunately, current knowledge of the morphology of the Palaearctic spe- cies of Petasiger does not permit reliable species identification, since existing morphometric data for the three species under study exhibit overlapping ranges for all characters with the exception of the cirrus-sac length (see Fuhrmann, 1927; Ishii, 1935; Yamaguti, 1939; Mendheim, 1940; in Skrjabin \& Bashkirova, 1956; Prudhoe, 1945; Skrjabin \& Bashkirova, 1956; Macko, 1959; Odening, 1962; Odening, 1965; Cankovic et al., 1983; Borgarenko, 1984; Chen et al., 1985; Iskova, 1985).

The results of the univariate and multivariate statistical analyses presented here, although carried out on a restricted set of characters and specimens, demonstrate that reliable morphometric differences supporting the distinct status of the compared species do exist. Our data reveal a number of variables (BL, BW, ASL, DSL, DOS, DPH, DVS, DPT, OL and EL) that exhibit important morphometric differences between the three species. Although the material did not permit the acquisition of sufficient data on the measurements of spines and eggs for each specimen to include these variables 

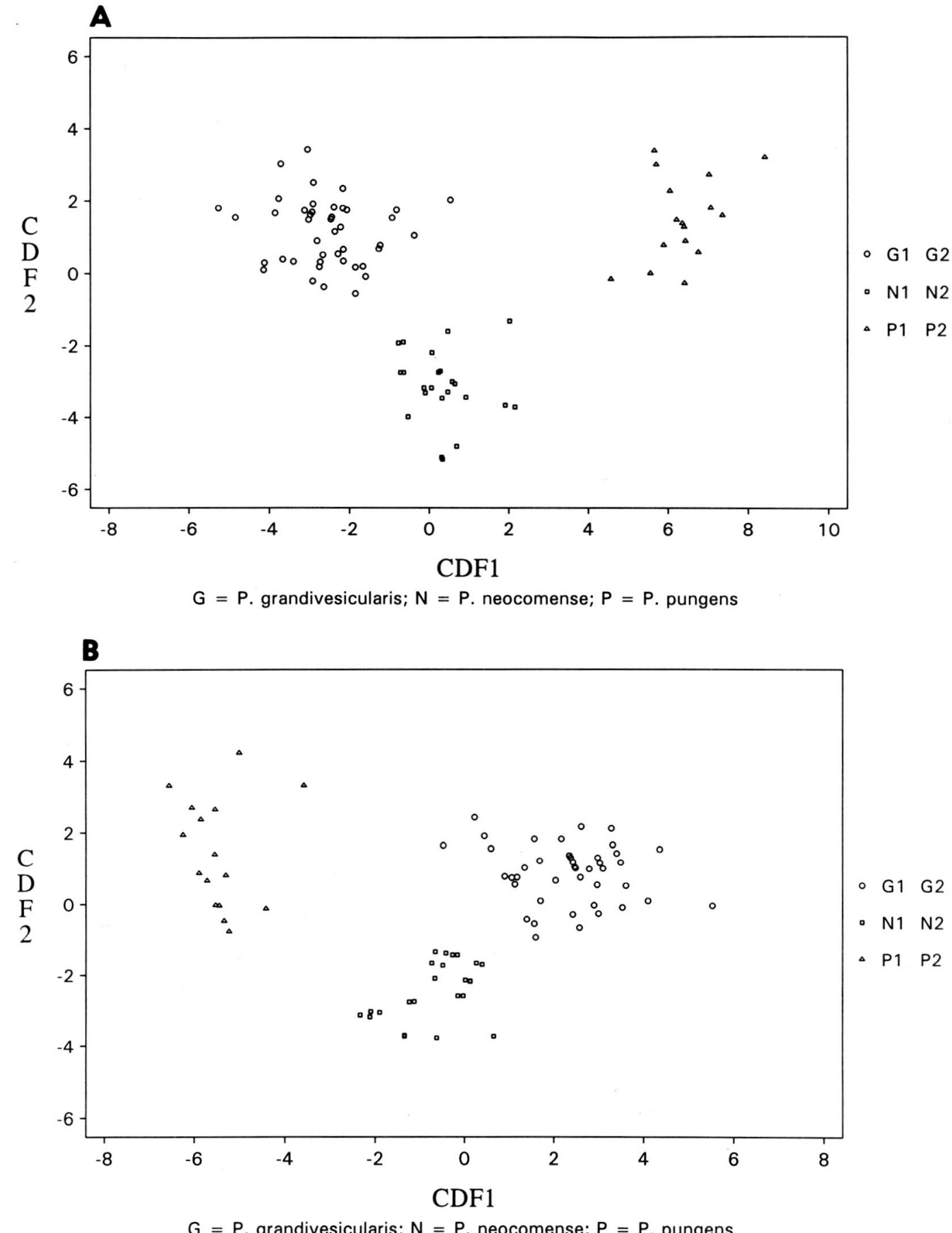

Fig. 2. - Scatterplot of the discriminant scores of specimens belonging to the three species of Petasiger. A. Canonical discriminant functions CDF1 and CDF2 derived using 82 specimens and 6 variables (Variant 1). B. Canonical discriminant functions CDF1 and CDF2 derived using 85 specimens and 2 variables (DPH and OL). 


\begin{tabular}{|c|c|c|c|c|c|c|}
\hline \multirow[b]{2}{*}{ Variable } & \multicolumn{2}{|c|}{$\begin{array}{c}\text { Variant } \mathbf{1} \\
(n=82)\end{array}$} & \multicolumn{2}{|c|}{$\begin{array}{c}\text { Variant } 2 \\
(n=63)\end{array}$} & \multicolumn{2}{|c|}{$\begin{array}{c}\text { Variant } 3 \\
(n=58)\end{array}$} \\
\hline & CDF1 & $\mathrm{CDF} 2$ & CDF1 & CDF2 & CDF1 & CDF2 \\
\hline DPH & $0.805^{*}$ & -0.404 & $0.580^{*}$ & -0.509 & $0.623^{*}$ & 0.453 \\
\hline $\mathrm{OL}$ & 0.054 & $-0.808^{*}$ & -0.045 & $-0.804^{*}$ & -0.051 & $0.696^{*}$ \\
\hline DPT & 0.252 & 0.066 & 0.179 & 0.124 & 0.254 & 0.035 \\
\hline DVS & 0.131 & -0.261 & 0.034 & -0.222 & 0.129 & 0.356 \\
\hline $\mathrm{BL}$ & 0.361 & -0.290 & 0.215 & -0.269 & 0.306 & 0.382 \\
\hline $\mathrm{BW}$ & 0.269 & -0.105 & $-{ }^{* *}$ & - & 0.296 & 0.263 \\
\hline DOS & - & - & 0.379 & -0.315 & 0.470 & 0.416 \\
\hline
\end{tabular}

** Variable excluded from the model.

Table IV. - Comparative data on the pooled-within groups correlations between the variables and the canonical discriminant functions $(\mathrm{CDFs})$. The values indicating the highest correlation of a variable with the CDF are marked with an asterisk.

in the discriminant analysis, the univariate tests suggest that these features also contribute to the discrimination of the three taxa. However, the variability of some characters, as indicated by their CLs and CDF scores, suggest the need for detailed studies on the inter-populational variability within Petasiger spp. All these considerations point to the desirability of a thorough review of the genus Petasiger with re-descriptions of the valid species.

\section{ACKNOWLEDGEMENT}

T his study was completed with the financial support to one of the authors (AK) by the National Scientific Research Foundation of the Republic of Bulgaria, grant B-315.

\section{REFERENCES}

BASHKIROVA E.Y. Bird echinostomids in the USSR with a review of their life-cycles. Trudy Bashkirskoy Nauchno-issledovatel'skoy Veterinarnoy Stantsii, 1941, 3, 243-300 (in Russian).

BORgarenKo L. Helminths of birds from Tadzhikistan, II. Trematodes, Izdatel'stvo Donish, Dushanbe, 1984, 29 (in Russian).

Cankovic M., KazIC D. \& Rozman M. Helmintofauna vodenih ptica iz familije Podicipidae Skadarskog jezera. Veterinaria-Sarajevo, 1983, 32, 181-193.

Chen H.T. (Ed.). Fauna Sinica. Platyhelminthes. Trematoda. Digenea (I), Science Press, Beijing, 1985, 406-407 (in Chinese).

Di Deco M.A., Orecchia P., Paggi L. \& Petrarca V. Morphometric stepwise analysis of three genetically identified species within Pseudoterranova decipiens (Krabbe, 1878) (Nematoda: Ascaridida). Systematic Parasitology, 1994, 29, 81-89.
Dietz E. Die Echinostomiden der Vögel. Zoologisher Anzeiger, 1909, 34, N 6, 180-192.

Fuhrmann O. Petasiger neocomense nov. sp. Une nouvelle espèce d'Echinostomides. Extraits, Bulletin de la Société Neuchâteloise des Sciences Naturelles, 1927, 1, 3-6.

Georgiev B., Biserkov V. \& Genov T. In toto staining method for cestodes with iron acetocarmine. Helminthologia, 1986, 23, 279-281.

IsHi N. Studies on bird trematodes. III. Bird trematodes in Japan (Continued). IV. Seven new bird trematodes. Japanese Journal of Experimental Medicine, 1935, 13, 275284 .

Iskova N.I. Echinostomatata, in: Sharpilo V.P. (ed.). Fauna Ukrainy. Izdatel'stvo Naukova Dumka, Kiev, 1985, 62-63 (in Russian).

Karmanova E.M. The life-cycle of Petasiger neocomense (Trematoda, Echinostomatidae). Trudy Gel'mintologicheskoi Laboratorii, 1971, 21, 31-35 (in Russian).

Kostadinova A. \& Chipev N. Experimental data on the lifecycle of Petasiger grandivesicularis Ishii, 1935 (Trematoda: Echinostomatidae). Systematic Parasitology, 1992, 23, 5565.

Kostadinova A. \& Gibson D.I. Petasiger oschmarini n. sp. (Digenea: Echinostomatidae) in the grebes Podiceps grisegana (Bod.) and P. auratus (L.) (Aves: Podicipedinae) from Kamchatka, Russia. Systematic Parasitology (in press).

MACKO J.K. K helmintofaune potápkovitých vtákov na Východnom Slovensku, Ceskoslovenská Parasitologie, 1959, 6, 127-158 (in Czech).

Mendherm H., Beitrage zur Systematic und Biologie der Familie Echinostomatidae. Archiv für Naturgeschichte, 1943, 12, N 2, 175-302.

Nasir P., Gonzalez T. \& Diaz M. Freshwater larval trematodes. XXX. Life cycle of Petasiger novemdecim Lutz, 1928. Proceedings of the Helminthological Society of Washington, 1972, 39 (2), 162-168.

Norusis M.J. SPSS/PC+ Advanced Statistics 4.0. SPSS Inc., $1990,373 \mathrm{p}$. 


\section{KOSTADINOVA A., GIBSON D.I. \& GUBÁNYI A.}

OdenING K. Trematoden aus einheimischen Vögeln des Berliner Tierparks und der Umgebung von Berlin. Biologischen Zentralblatt, 1962, 81 (4), 419-468.

Odening K. Zur Trematodenfauna der einheimischen Lappentaucher und des Bleßhuhns. Abhandlungen und Berichte für Naturkunde und Vorgeschichte, 1965, 11, 119-132.

PRUdHoe S. On two echinostome trematodes from grebes. Annals and Magazine of Natural History, 1945, Ser. II., 11, 1-8.

SkRJABin K.I. \& BashKirova E.Y. Family Echinostomatidae, in: Skrjabin K.I. (ed.), Trematodes of animals and man. Izdatel'stvo Akademii Nauk SSSR, Moskva, 1956, vol. 12, 501-546 (in Russian).

SOKal R.R. \& Rolf F.J. Biometry. The Principles and Practice of Statistics in Biological Research. (2nd ed.). W.H. Freeman \& Co, New York, 1981, 859 p.

Yamagutt S. Studies on the helminth fauna of Japan. Trematodes of birds, IV. Japanese Journal of Zoology, 1939, 8 (2), 131-210.

Yamaguti S. Systema Helminthum. Intersciences Publishers Co., New York, 1958, vol. 1, 1,575 p.

Reçu le 11 février 1997 Accepté le 18 août 1997 